\title{
Accumulation of Mast Cells in the Lesions and Effects of Antiallergic Drugs on the Patients with Inflammatory Bowel Disease
}

\author{
Motohiro Kurosawa $^{1}$ and Hiroichi Nagai ${ }^{2}$ \\ ${ }^{1}$ Department of Allergy and Respiratory Medicine, Tatebayashi-Kosei Hospital, 262-1 Narushima, Tatebayashi, \\ Gunma 374-8533, Japan \\ ${ }^{2}$ Gifu Junior College of Health Science, 2-92 Higashi-uzura, Gifu 500-8281, Japan
}

Correspondence should be addressed to Motohiro Kurosawa; motohiro@kl.wind.ne.jp

Received 22 September 2012; Revised 14 April 2013; Accepted 17 April 2013

Academic Editor: Aleem Ahmed Khan

Copyright (C) 2013 M. Kurosawa and H. Nagai. This is an open access article distributed under the Creative Commons Attribution License, which permits unrestricted use, distribution, and reproduction in any medium, provided the original work is properly cited.

The pathomechanism of inflammatory bowel disease (IBD) has not yet been fully demonstrated. However, it is well known that mast cells are present in the gastrointestinal tract, suggesting that mast cells may take part in it. So, we investigated the number of mast cells in IBD, such as ulcerative colitis (UC) and eosinophilic colitis, and showed that the number of mast cells was increased in the inflammatory lesions. We also presented a case of UC which was treated successfully with an antiallergic drug, tranilast. Furthermore, possible new approaches to treating the disease with immunomodulators including suplatast are introduced. However, our investigations were performed with a limited number of patients with IBD, and additional further studies are required to confirm the findings.

\section{Introduction}

Many reports identified changes in mast cells in inflammatory bowel disease (IBD) including ulcerative colitis (UC). $\mathrm{UC}$ is chronic inflammatory bowel disorder which shows evidence of activation of the immune system of the colorectum, with exacerbations and remissions [1-5]. However, contradicting data have also been reported regarding the distribution of mast cells in the intestinal mucosa of patients with UC; namely, the number was increased in some studies $[6,7]$, unchanged [8], and decreased in others [9]. One reason for the discrepancy in mast cell distribution in colonic lesions may be due to differences in the methods used for tissue preparation, such as tissue fixation, staining techniques, and methods of cell counting as described by Craig et al. [10]. In fact, conventional staining methods are inferior to the sensitive immunohistochemical techniques that use antibodies to specific mast cell proteinase such as tryptase, and some immunohistochemical studies have noted that one of the features of UC among IBDs may be a marked increase of mast cells in the affected mucosa [11, 12].

Eosinophilic colitis (EC), a subtype of eosinophilic gastroenteritis, is a disease characterized by peripheral blood eosinophilia and a prominent eosinophilic infiltration in the intestinal mucosa. Some reports suggested possible involvement of food allergy as the mechanism of the disease $[13,14]$. Bischoff [15] reported that eosinophils and mast cells seemed to be mutually related in the allergic reaction in digestive tract mucosa. Although mast cells are thought to be critical effector cells in gastrointestinal allergic reactions [16-18], the role of mast cells in EC still remains unclear.

In this paper, we investigated the number of mast cells in UC and EC using immunohistochemical staining for human mast cell tryptase $[19,20]$. We also reconsider the valuable effect of antiallergic drugs on the treatment of patients with UC as Melamed et al. [21] reported a beneficial effect of ketotifen on patients with eosinophilic gastroenteritis. All our studies in the present paper were performed with the approval 
of the Institutional Ethics Committee of Gunma Institute for Allergy and Asthma, Gunma Hospital for Allergic and Respiratory Diseases, where the corresponding author has worked until March 2013, and written informed consent was obtained from each individual before the study commenced.

\section{Quantitative Analysis of Mast Cells in the Active Stage and in Remission in the Same Patients with UC}

The diagnosis of UC was based on evaluating pathologic interpretation of biopsy specimens in conjunction with clinical, laboratory, radiologic, and endoscopic features as reported [22]. Important features of untreated UC in biopsy specimens include diffuse involvement of the colorectum without skip lesions, lack of submucosal involvement, lack of granulomas, and lack of terminal ileum involvement. In the active stage, in addition to erosion and ulceration of the lining epithelium of the mucosa, the mucous membrane was inflamed and its capillary blood vessels were dilated and engorged. The epithelium of the crypts was depleted of goblet cells, and crypt abscess formation was observed. There was an inflammatory cell infiltration such as lymphocytes and plasma cells in the lamina propria. On the other hand, the mucous membrane became atrophic, and the epithelial glands were found to be irregular and short in the same patients in remission.

An immunohistochemical method as described in [19, 20] was used for the detection of mast cells. In brief, serial sections of biopsy specimens were incubated in a humid chamber overnight at $4^{\circ} \mathrm{C}$ with a monoclonal murine antitryptase antibody (Chemicon, Temecula, CA, USA) diluted 1:400 in Tris buffer (50 mM Tris-HCl buffer, $\mathrm{pH}$ 7.6) containing $1 \%$ bovine serum albumin. The sections were then washed extensively in running TTBS buffer $(50 \mathrm{mM}$ Tris$\mathrm{HCl}, 154 \mathrm{mM} \mathrm{NaCl}, 0.05 \%$ Tween-20, $\mathrm{pH} 7.4$ ) at $4^{\circ} \mathrm{C}$ for 10 seconds, followed by washing extensively in TTBS buffer for 15 minutes at room temperature (with 3 changes of buffer) and washing in distilled water for 5 minutes. The sections were incubated for 40 minutes in a humid chamber at room temperature with a rabbit anti-mouse immunoglobulin antibody (Dako, Carpinteria, CA, USA) diluted 1:100 with Tris buffer followed by washing in TTBS buffer for 15 minutes at room temperature (with 3 changes of buffer) and washing in distilled water for 5 minutes. Sections were then incubated for 40 minutes in a humid chamber at room temperature with a monoclonal anti-alkaline phosphatase antibody conjugated to alkaline phosphatase (APAAP complex; Dako) diluted 1:50 in Tris buffer. The sections were washed extensively in running TTBS buffer at $4^{\circ} \mathrm{C}$ for 10 seconds, then washed in TTBS buffer for 15 minutes at room temperature (with 3 changes of buffer), and washed in distilled water for 5 minutes. Isotype control of antibodies was used in the staining process. Color was developed for 10 minutes at room temperature with a fast red substrate containing naphthol AS-MX phosphate (Dako) (100 mM Tris-HCl buffer, pH 8.2, containing naphthol phosphate, fast red, and levamisole). The sections were washed with distilled water, counterstained

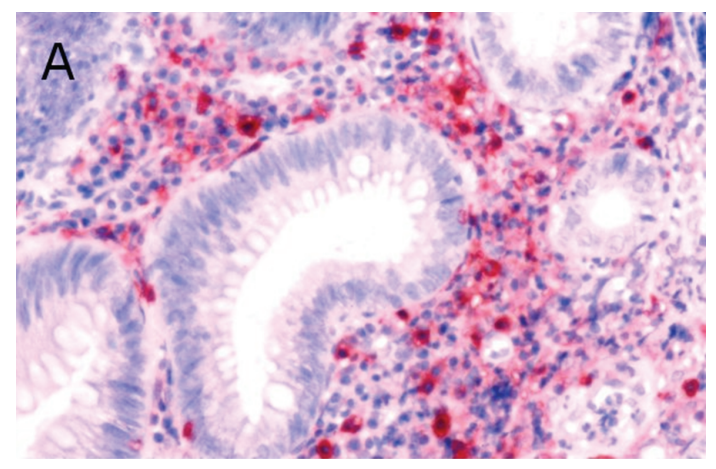

(a)

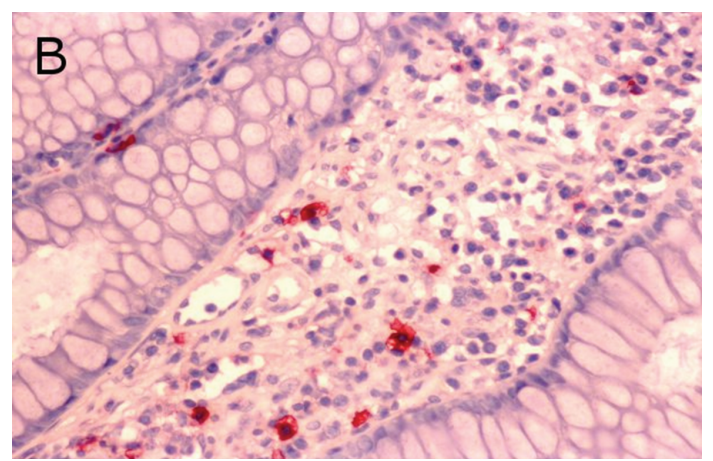

(b)

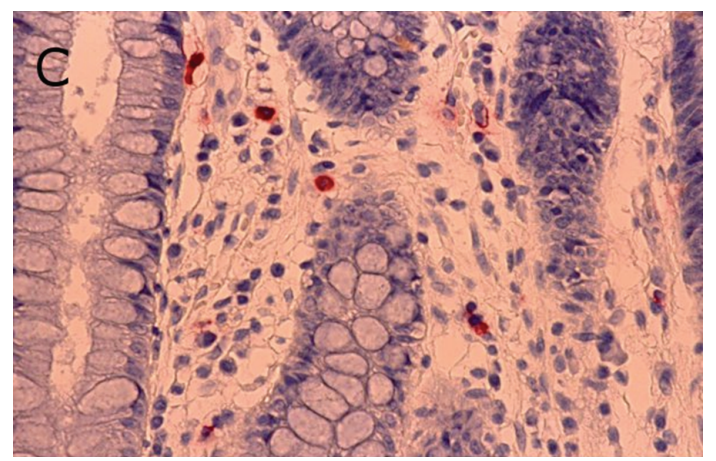

(c)

FIgURE 1: Immunohistochemical staining for human mast cell tryptase of serial sections of the lesional tissue from a patient with UC. (a) Lesional tissue from a patient with UC in active stage; (b) lesional tissue from the same patient with UC in remission; (c) adjacent control tissue from a healthy volunteer who visited our clinic for annual physical examination. Immunohistochemical staining for mast cell was performed with the protocol as described precisely in the text. Under 400x magnification.

with Mayer's hematoxylin for 5 minutes, and then washed in running water for 10 minutes and mounted in glycerol gelatin (Sigma, St. Louis, MO, USA). Photomicrographs were taken with an Olympus PM-10AK and an Olympus BX-50 microscope.

Here we examined the number of mast cells in UC. Figure 1 shows immunohistochemical staining for mast cell tryptase in the active stage and in remission of a patient with UC and the adjacent healthy tissue from a healthy control. 


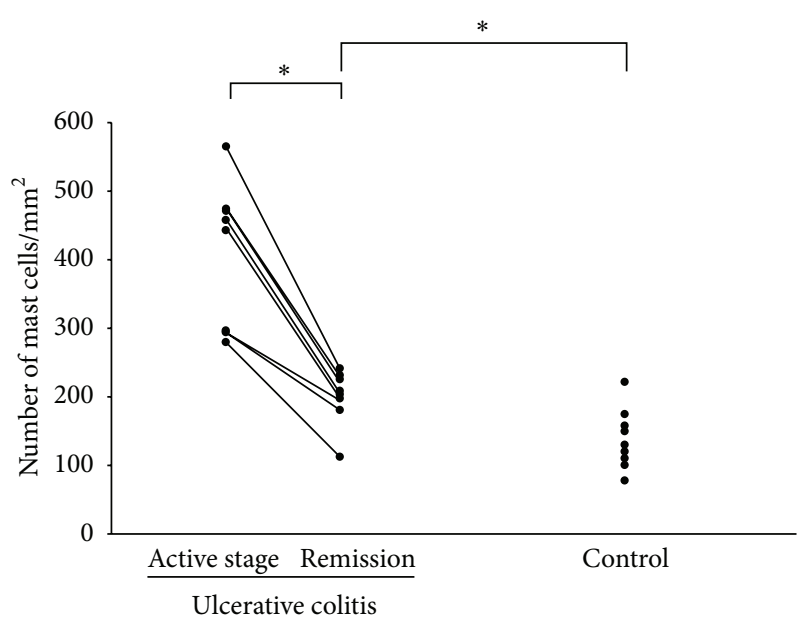

Figure 2: Number of mast cells in the lesional tissue from eight patients with UC. The number was compared between active stage and remission in the same patients. In addition, the number was compared between the lesions and adjacent healthy tissues in nine healthy volunteers who visited our clinic for annual routine physical examination, which comprised the healthy controls. Data were analyzed with non-parametric Kruskall-Wallis and Mann-Whitney tests. Collated specimens were analyzed with Wilcoxon test for non-parametric data, Statistical significance between the groups as indicated at ${ }^{*} P<0.05$.

Accumulation of mast cells in the active stage of the patient was clearly observed (Figure 1(a)). Then, we investigated the number of mast cells in the active stage and in remission in eight patients with UC and compared the number of mast cells with that in adjacent healthy tissues from nine healthy volunteers who visited our clinic for annual routine physical examinations, which comprised the healthy controls [19]. The range of the number of mast cells in our study was in agreement with others $[8,12,23]$. The median of the number of mast cells in the active stage and that in remission of the same patients were $451 / \mathrm{mm}^{2}$ with a range from 280 to $566 / \mathrm{mm}^{2}$ and $206 / \mathrm{mm}^{2}$ with a range from 112 to $241 / \mathrm{mm}^{2}$, respectively. A significant accumulation of mast cells in the active stage was present compared with that in remission of UC $(P<0.05)$. Also, our research has brought us to the realization that the number of mast cells in UC in remission was significantly greater than that in adjacent healthy controls $(P<0.05)$ (Figure 2).

\section{Accumulation of Mast Cells in the Interstitium of EC}

EC colitis is a subtype of eosinophilic gastroenteritis. Histologic evidence of a predominant eosinophilic infiltration in the gastrointestinal mucosa in the absence of parasitic infection and extraintestinal diseases confirms a diagnosis of eosinophilic gastroenteritis. In some patients of EC, food allergy seemed to be associated with the disease [13]. However, direct evidence of allergy, such as involvement of mast cells, has not been consistently confirmed in EC.
A 35-year-old man suffering from consistent diarrhea was introduced to our clinic because of peripheral blood eosinophilia (17.9\%). No remarkable finding was observed on physical examination, and stool culture was negative for pathological bacteria and no parasitic infections were noted too. Diagnosis of EC was made with histological findings of biopsy specimens from colon, which showed numerous eosinophil infiltration in the interstitium and edematous change of the tissue. Then, we examined the number of mast cells in the interstitium from the patient with EC [20]. The mean number of mast cells in ascending colon and rectum was $352 / \mathrm{mm}^{2}$ and $405 / \mathrm{mm}^{2}$, respectively. We could not investigate the number of mast cells in colon when the patient's condition became well because the informed consent of the test was not obtained. So as controls, biopsy specimens were obtained from the same site in five normal volunteers, and we examined the number of mast cells for comparison. The mean number of mast cells in normal control in ascending colon and rectum was $150 \pm 16$ (mean \pm $\mathrm{SD}) / \mathrm{mm}^{2}$ and $126 \pm 63 / \mathrm{mm}^{2}$, respectively. Sasaki et al. [11] reported in their study that the number of mast cells in ascending colon and rectum from normal control was $122 \pm 18$ cells $/ \mathrm{mm}^{2}$ and $110 \pm 16 \mathrm{cells} / \mathrm{mm}^{2}$, respectively, and their findings are consistent with those of our study.

Taken together, our findings suggested that the number of mast cells in the interstitium of EC might be increased. However, as far as we have examined literature, there has been no case report of EC in which the number of mast cells was examined. Therefore, further studies are required to confirm our findings.

\section{Antiallergic Drug Use in Japan for the Treatment of Allergic Diseases: The Rationale and the Clinical Outcome}

As noted by European and American clinicians, a distinct characteristic of Japanese asthma prescribing is the reliance on prophylactic antiallergic drugs, especially oral ones [2426].

As the concept of "prophylaxis" for this category of drugs was imported from Europe, we expected some difficulties for its acceptance in Japan. However, judging from the present status of these drugs in Japan, it is clear that prophylactic therapy has been well accepted by Japanese clinicians and patients. There are two major reasons for this phenomenon: one is the previous experience of Chinese medications for long-term use by Japanese people, and the other, which is even more important, is the close relationship between doctors and patients in Japan. Under these unique circumstances, long-term therapy can be realized within a well-organized therapeutic program.

Another factor for the success of prophylactic antiasthma drugs in Japan may be their increasing availability. They are available for use in infants to aged patients in a variety of formulations including syrup, dry syrup, capsule, and tablet form. In addition, these prophylactic agents are being used for various allergic diseases such as allergic rhinitis and atopic dermatitis as well as bronchial asthma. 


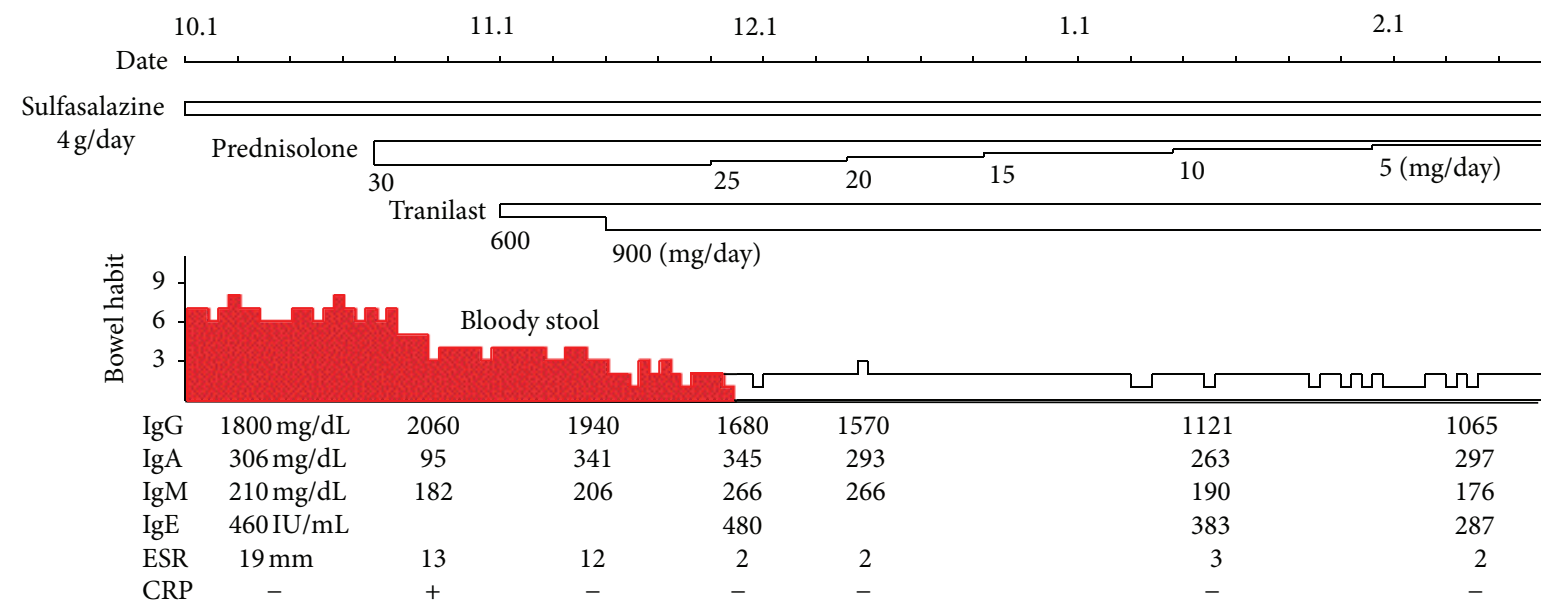

FIGURE 3: Clinical course of a patient with UC treated successfully with tranilast and sulfasalazine.

In a study of multiple anthranilic acid derivatives, Koda et al. [27] found antiallergic properties in a new compound, $\mathrm{N}-\left(3^{\prime}, 4^{\prime}\right.$ dimethoxycinnamoyl) anthranilic acid $\left(\mathrm{N}-5^{\prime}\right.$, tranilast), when given orally. Tranilast is an orally active antiallergic drug, and first reports describing its antiallergic properties appeared in 1976 [27, 28]. Tranilast has been available in Japan since 1983 for the treatment of allergic diseases including bronchial asthma, allergic rhinitis, and allergic skin disorders.

\section{Therapeutic Trial of Antiallergic Drugs in the Treatment of UC}

A 23-year-old female was diagnosed as UC (proctitis type) based on her present history, barium enema, and sigmoidoscopy, and the patient was successfully treated with tranilast as reported in [29].

In the case, serum immunoglobulin (Ig) $\mathrm{A}$ and $\mathrm{CH}_{50}$ levels were slightly lowered from normal levels, and skin tests to several inhalant and food antigens showed positive reactions. Although her clinical symptoms were not improved with sulfasalazine and betamethasonum suppository treatment, they were improved by the administration of tranilast. Thereafter, with tranilast her condition stabilized without the medication of sulfasalazine, and the ulcer of rectum disappeared. Therefore, we examined the effect of antiallergic drugs on the treatment of UC.

The other seven patients with UC (one was proctitis and six were left-sided colitis) were treated successfully with antiallergic drugs such as tranilast [30,31]. The clinical course of one of the patients, who was successfully treated with tranilast and sulfasalazine, is shown in Figure 3. Before the therapy, the patient complained a frequent bowel habit with bloody stool and abdominal pain. The serological examination showed slight increases of serum IgG, IgE, and CRP levels. The patient was clinically well treated by tranilast and sulfasalazine, and the amount of steroid administration was reduced and bowel habit became normal.

\section{Possible Pharmacological Acting Points of Suplatast on the Pathogenesis of IBD}

There is considerable cumulative clinical evidence for mast cell involvement in IBD as follows. In the colorectal mucosa from patients with UC, mast cell tryptase level was significantly increased in the lamina propria and submucosa [32]. The increased number of mast cells found in the colonic mucosa of IBD patients was accompanied by dramatically increased expression of tumor necrosis factor (TNF) $\alpha$, interleukin (IL)-16, and substance P [33]. Findings of mast cell degranulation were observed in the intestinal wall of IBD patients, suggesting that mast cell degranulation may be involved in the pathogenesis of IBD [33].

Mast cells release a number of proinflammatory mediators, and the cells have the capacity to produce a variety of cytokines. Dozens of proinflammatory cytokines were reported to be involved in the pathogenesis of IBD. TNF $\alpha$ was considered to be secreted mainly from intestinal mast cells in IBD [33-36], and bacteria and anti-IgE were able to substantially enhance the release from mast cells [36]. $\mathrm{TNF} \alpha$ and histamine released from mast cells could synergistically stimulate ion secretion from intestinal epithelium [37]. Intestinal mast cells in IBD produce IL-3 [38]. IL-1 was excessively released from patients with UC [39]. Interestingly, mast cells from healthy controls did not produce IL-5, but mast cells from patients with IBD released a relatively large amount of IL-5 [40].

In addition to mast cells, the role of $\mathrm{T}$ cells in the pathogenesis of IBD was widely investigated [41-51]. According to the current paradigm, IBDs including Crohn's disease and UC occur in predisposed individuals to dysregulated immune $\mathrm{T}$ cell response. In general, imbalance of Th1/Th2 response is important pathogenetic value at chronic inflammatory process. In this decade, tissue injury in IBD is thought to be primarily mediated by Thl dominant immune response in Crohn's disease and Th2 response in UC. However, the discoveries of new subsets of T-helper cells, especially Th17 cells, added a new understanding of the disease. 
TABLE 1: Basic pharmacological activity of IPD.

(A) Immunomodulating activity

(1) Suppression of IgE antibody production (murine, cultured human cell)

(2) Suppression of Th2 cytokine production (murine, human cell)

(3) Suppression of thymus and activation-regulated chemokine (TARC) production

(4) Modulation of toll-like receptors 2 and 4 on antigen-presenting cells in rats

(5) Augmentation of aging-induced downregulated IgE production in mice

(B) Anti-inflammatory activity

(1) Inhibition of histamine release from rat mast cells

(2) Inhibition of murine eosinophil chemotaxis

(3) Inhibition of EG2 positive eosinophil and CD4 or CD25 positive T-cell accumulation in human airway

(4) Inhibition of human eosinophil degranulation

(5) Inhibition of IL-4 induced vascular cell adhesion molecule 1 (VCAMI) expression on human umbilical vein endothelial cells

(C) Experimental asthma

(1) Inhibition of air-flow limitation (mice, guinea pigs)

(2) Inhibition of airway hyperresponsiveness (mice, guinea pigs)

(3) Inhibition of goblet-cell metaplasia of mice airway epithelium

The imbalance or polarization of Th1, Th2, Th17, and other $T$ cell subgroups are nominated in the pathogenesis of IBD. The elucidation of pathophysiology of IBD stimulates the research on pharmacological studies for therapy. The agents which adjust the imbalance of $\mathrm{T}$ cell subset or potentiate the regulatory cytokines show a therapeutic potential in the treatment of experimental IBDs [52-56]. The previous results suggest the possibility of immunomodulating agents for clinical application as a remedy for IBD.

During our investigation of antiallergic drugs, vitamin $U$ derivative, suplatast was found to have potent immunomodulating and anti-inflammatory activity in Th2 polarized immune processes [57-60]. Table 1 shows a summary of the basic research on the pharmacological activity of suplatast as reported [60]. Suplatast shows both the inhibition of mast cell activation and Th2 polarized immune response. These pharmacological profiles suggest the possible application of suplatast for management of IBD. Whereas there is scarcely any opportunity to see any reference concerning the clinical trial on the application of suplatast for the management of IBD, the previous basic data suggest the possible efficacy of suplatast.

\section{Conclusions}

The precise pathomechanism of IBD remains unknown. However, there is growing evidence that mast cells take part at least in the course of the disease. Current data about the increased number of mast cells in the inflammatory lesions of the disease and those about the role of mast cellderived mediators and cytokines in IBD should be taken into consideration when new approaches to treating the diseases will be introduced. Immunomodulators, such as suplatast, may become one of the target drugs for the treatment of the disease. However, our investigations were performed with a limited number of patients with IBD, and additional further studies are required to confirm the findings.

\section{Conflict of Interests}

None of the authors have any conflict of interests.

\section{References}

[1] J. K. Ritchie, J. Powell-Tuck, and J. E. Lennard-Jones, "Clinical outcome of the first ten years of ulcerative colitis and proctitis," The Lancet, vol. 1, no. 8074, pp. 1140-1143, 1978.

[2] F. C. Edwards and S. C. Truelove, "The course and prognosis of ulcerative colitis," Gut, vol. 4, pp. 299-315, 1963.

[3] E. Langholz, P. Munkholm, M. Davidsen, and V. Binder, "Course of ulcerative colitis: analysis of changes in disease activity over years," Gastroenterology, vol. 107, no. 1, pp. 3-11, 1994.

[4] N. Hiwatashi, T. Yao, H. Watanabe et al., "Long-term follow-up study of ulcerative colitis in Japan," Journal of Gastroenterology, vol. 30, supplement 8, pp. 13-16, 1995.

[5] W. Selby, “The natural history of ulcerative colitis," Bailliere's Clinical Gastroenterology, vol. 11, no. 1, pp. 53-64, 1997.

[6] C. C. Fox, A. J. Lazenby, W. C. Moore, J. H. Yardley, T. M. Bayless, and L. M. Lichtenstein, "Enhancement of human intestinal mast cell mediator release in active ulcerative colitis," Gastroenterology, vol. 99, no. 1, pp. 119-124, 1990.

[7] T. King, W. Biddle, P. Bhatia, J. Moore, and P. B. Miner, "Colonic mucosal mast cell distribution at line of demarcation of active ulcerative colitis," Digestive Diseases and Sciences, vol. 37, no. 4, pp. 490-495, 1992.

[8] S. C. Bischoff, J. Wedemeyer, A. Herrmann et al., "Quantitative assessment of intestinal eosinophils and mast cells in inflammatory bowel disease," Histopathology, vol. 28, no. 1, pp. 1-13, 1996.

[9] G. Lloyd, F. H. Green, H. Fox, V. Mani, and L. A. Turnberg, "Mast cells and immunoglobulin $\mathrm{E}$ in inflammatory bowel disease," Gut, vol. 16, no. 11, pp. 861-865, 1975.

[10] S. S. Craig, G. DeBlois, and L. B. Schwartz, "Mast cells in human keloid, small intestine, and lung by an immunoperoxidase technique using a murine monoclonal antibody against tryptase," The American Journal of Pathology, vol. 124, no. 3, pp. 427-435, 1986. 
[11] Y. Sasaki, M. Tanaka, and H. Kudo, "Differentiation between ulcerative colitis and Crohn's disease by a quantitative immunohistochemical evaluation of T lymphocytes, neutrophils, histiocytes and mast cells," Pathology International, vol. 52, no. 4, pp. 277-285, 2002.

[12] Y. Nishida, K. Murase, H. Isomoto et al., "Different distribution of mast cells and macrophages in colonic mucosa of patients with collagenous colitis and inflammatory bowel disease," Hepato-Gastroenterology, vol. 49, no. 45, pp. 678-682, 2002.

[13] A. M. Saavedra-Delgado and D. D. Metcalfe, "Interactions between food antigens and the immune system in the pathogenesis of gastrointestinal diseases," Annals of Allergy, vol. 55, no. 5, pp. 694-702, 1985.

[14] I. Narama, K. Ozaki, S. Matsushima, and T. Matsuura, "Eosinophilic gastroenterocolitis in iron lactate-overloaded rats," Toxicologic Pathology, vol. 27, no. 3, pp. 318-324, 1999.

[15] S. C. Bischoff, "Mucosal allergy: role of mast cells and eosinophil granulocytes in the gut," Bailliere's Clinical Gastroenterology, vol. 10, no. 3, pp. 443-459, 1996.

[16] R. F. Lemanske Jr., F. M. Atkins, and D. D. Metcalfe, "Gastrointestinal mast cells in health and disease. Part II," The Journal of Pediatrics, vol. 103, no. 3, pp. 343-351, 1983.

[17] N. Oyaizu, Y. Uemura, H. Izumi, S. Morii, M. Nishi, and K. Hioki, "Eosinophilic gastroenteritis: immunohistochemical evidence for IgE mast cell-mediated allergy," Acta Pathologica Japonica, vol. 35, no. 3, pp. 759-766, 1985.

[18] B. K. Wershil, "Role of mast cells and basophils in gastrointestinal inflammation," Chemical Immunology, vol. 61, no. 1, pp. 187203, 1995.

[19] Y. Kashiwase, H. Inamura, J. Morioka, Y. Igarashi, K. KawaiKowase, and M. Kurosawa, "Quantitative analysis of mast cells in benign and malignant colonic lesions: immunohistochemical study on formalin-fixed, paraffin-embedded tissues," Allergologia et Immunopathologia, vol. 36, no. 5, pp. 271-276, 2008.

[20] H. Inamura, Y. Kashiwase, J. Morioka, K. Suzuki, Y. Igarashi, and M. Kurosawa, "Accumulation of mast cells in the interstitium of eosinophilic colitis," Allergologia et Immunopathologia, vol. 34, no. 5, pp. 228-230, 2006.

[21] I. Melamed, S. J. Feanny, P. M. Sherman, and C. M. Roifman, "Benefit of ketotifen in patients with eosinophilic gastroenteritis," The American Journal of Medicine, vol. 90, no. 3, pp. 310-314, 1991.

[22] R. Odze, "Diagnostic problems and advances in inflammatory bowel disease," Modern Pathology, vol. 16, no. 4, pp. 347-358, 2003.

[23] G. F. A. Benfield, R. Bryan, and J. Crocker, "Lamina propria eosinophils and mast cells in ulcerative colitis: comparison between Asians and Caucasians," Journal of Clinical Pathology, vol. 43, no. 1, pp. 27-31, 1990.

[24] M. Kurosawa, "Prophylactic antiasthma drugs in Japan," Journal of Asthma, vol. 27, no. 5, pp. 299-306, 1990.

[25] M. Kurosawa, "The prophylactic use of anti-asthma drugs in Japan," ACI News, vol. 4, no. 5, pp. 135-139, 1992.

[26] M. Kurosawa, "Anti-allergic drug use in Japan: the rationale and the clinical outcome," Clinical and Experimental Allergy, vol. 24, no. 4, pp. 299-306, 1994.

[27] A. Koda, H. Nagai, and S. Watanabe, "Inhibition of hypersensitivity reactions by a new drug, $\mathrm{N}\left(3^{\prime}, 4^{\prime}\right.$ dimethoxycinnamoyl) anthranilic acid (N-5')," Journal of Allergy and Clinical Immunology, vol. 57, no. 5, pp. 396-407, 1976.
[28] H. Azuma, K. Banno, and T. Yoshimura, "Pharmacological properties of $\mathrm{N}\left(3^{\prime}, 4^{\prime}\right.$ dimethoxycinnamoyl) anthranilic acid $\left(\mathrm{N}-5^{\prime}\right)$, a new anti atopic agent," British Journal of Pharmacology, vol. 58, no. 4, pp. 483-488, 1976.

[29] M. Kurosawa, T. Nemoto, T. Tanaka, R. Fueki, and S. Kobayashi, "A case of ulcerative colitis treated successfully with N- $\left(3^{\prime}, 4^{\prime}\right.$ dimethoxycinnamoyl) anthranilic acid $\left(\mathrm{N}-5^{\prime}\right)$," Arerugi, vol. 30, no. 1, pp. 8-15, 1981 (Japanese).

[30] M. Kurosawa, T. Nemoto, T. Tanaka et al., "A therapeutic trial of anti-allergic drugs in the treatment of ulcerative colitis," Clinical Immunology, vol. 14, supplement 1, pp. 127-137, 1982 (Japanese).

[31] S. Okamura, Y. Washida, and M. Kurosawa, "A case of ulcerative colitis treated successfully with anti-allergic drug," Biomedicine and Therapeutics, vol. 24, no. 10, pp. 1217-1219, 1990 (Japanese).

[32] M. Raithel, S. Winterkamp, A. Pacurar, P. Ulrich, J. Hochberger, and E. G. Hahn, "Release of mast cell tryptase from human colorectal mucosa in inflammatory bowel disease," Scandinavian Journal of Gastroenterology, vol. 36, no. 2, pp. 174-179, 2001.

[33] S. H. He, "Key role of mast cells and their major secretory products in inflammatory bowel disease," World Journal of Gastroenterology, vol. 10, no. 3, pp. 309-318, 2004.

[34] I. Lilja, C. Gustafson-Svard, L. Franzen, and R. Sjödahl, “Tumor necrosis factor-alpha in ileal mast cells in patients with Crohn's disease," Digestion, vol. 61, no. 1, pp. 68-76, 2000.

[35] M. Wierzbicki and E. Brezinska-Blaszczyk, "The role of mast cells in the development of inflammatory bowel diseases," Postepy Hig Med Dosw, vol. 21, no. 11, pp. 642-650, 2008 (Polish).

[36] S. C. Bischoff, A. Lorentz, S. Schwengberg, G. Weier, R. Raab, and M. P. Manns, "Mast cells are an important cellular source of tumour necrosis factor in human intestinal tissue," Gut, vol. 44, no. 5, pp. 643-652, 1999.

[37] J. C. J. Oprins, C. Van der Burg, H. P. Meijer, T. Munnik, and J. A. Groot, "Tumour necrosis factor $\alpha$ potentiates ion secretion induced by histamine in a human intestinal epithelial cell line and in mouse colon: involvement of the phospholipase D pathway," Gut, vol. 50, no. 3, pp. 314-321, 2002.

[38] M. Ligumsky, V. Kuperstein, H. Nechushtan, Z. Zhang, and E. Razin, "Analysis of cytokine profile in human colonic mucosal FceRI-positive cells by single cell PCR: inhibition of IL-3 expression in steroid-treated IBD patients," FEBS Letters, vol. 413, no. 3, pp. 436-440, 1997.

[39] T. D. Wardle and L. A. Turnberg, "Potential role for interleukin1 in the pathophysiology of ulcerative colitis," Clinical Science, vol. 86, no. 5, pp. 619-626, 1994.

[40] A. Lorentz, S. Schwengberg, C. Mierke, M. P. Manns, and S. C. Bischoff, "Human intestinal mast cells produce IL-5 in vitro upon IgE receptor cross-linking and in vivo in the course of intestinal inflammatory disease," European Journal of Immunology, vol. 29, no. 5, pp. 1496-1503, 1999.

[41] M. E. Himmel, Y. Yao, P. C. Orban, T. S. Steiner, and M. K. Levings, "Reguratory T-celly therapy for inflammatory bowel disease: more questions than answers," Immunology, vol. 136, no. 2, pp. 115-122, 2012.

[42] M. Gersemann, J. Wehkamp, and E. F. Stange, "Innate immune dysfunction in inflammatory bowel disease," Journal of Internal Medicine, vol. 271, no. 5, pp. 421-428, 2012.

[43] N. A. Hering, M. Fomm, and J. D. Shulzke, "Determinants of chronic barrier function in inflammatory bowel disease and potential therapeutics," Journal of Physiology, vol. 590, no. 5, pp. 1035-1044, 2012. 
[44] S. van der Marel, A. Majowicz, S. van Deventer, H. Petry, D. W. Hommes, and V. Ferreira, "Gene and cell therapy based treatment strategies for inflammatory bowel disease," World Journal of Gastrointestinal Pathophysiology, vol. 15, no. 2, pp. 114-122, 2011.

[45] Z. Liu, B. S. Feng, S. B. Yang, X. Chen, J. Su, and P. C. Yang, "Interleukin (IL)-23 suppresses IL-10 in inflammatory bowel disease," Journal of Biological Chemistry, vol. 287, no. 5, pp. 35913597, 2012.

[46] L. Bene, A. Falus, N. Baffy, and A. K. Fulop, "Cellular and molecular mechanisms in the two major forms of inflammatory bowel disease," Pathology and Oncology Research, vol. 17, no. 3, pp. 463-472, 2011.

[47] L. Pastorelli, R. R. Garg, S. B. Hoang et al., "Epithelial-derived IL-33 and its receptor ST2 are dysregulated in ulcerative colitis and in experimental Th1/Th2 driven enteritis," Proceedings of the National Academy of Sciences of the United States of America, vol. 107, no. 17, pp. 8017-8022, 2010.

[48] K. Ohtani, Y. Ohtsuka, T. Ikuse et al., "Increased mucosal expression of GATA-3 and STAT-4 in pediatric ulcerative colitis," Pediatrics International, vol. 52, no. 4, pp. 584-589, 2010.

[49] E. N. McNamee, J. D. Wermers, J. C. Masterson et al., "Novel model of Th2-polarized chronic ileitis : the SAMP1 mouse," Inflammatory Bowel Diseases, vol. 16, no. 5, pp. 743-752, 2010.

[50] I. J. Fuss, "Is the Th1/Th2 paradigm of immune regulation applicable to IBD?" Inflammatory Bowel Diseases, vol. 14, supplement 2, pp. S110-S112, 2008.

[51] F. Sanchez-Muñoz, A. Dominguez-Lopez, and J. K. YamamotoFurusho, "Role of cytokines in inflammatory bowel disease," World Journal of Gastroenterology, vol. 14, no. 27, pp. 4280-4288, 2008.

[52] E. Bailon, J. Roman, I. Ramis et al., "The new salicylate derivative UR-1505 modulates the Th2/humoral response in a dextran sodium sulphate model of colitis that resembles ulcerative colitis," Journal of Pharmacological Sciences, vol. 109, no. 2, pp. 315-318, 2009.

[53] H. Nakase, S. Mikami, and T. Chiba, "Alteration of CXCR4 expression and Th1/Th2 balance of peripheral CD4-positive $\mathrm{T}$ cells can be a biomarker for leukocytapheresis therapy for patients with refractory ulcerative colitis," Inflammatory Bowel Diseases, vol. 15, no. 7, pp. 963-964, 2009.

[54] R. Aharoni, O. Brenner, A. Cohen, and R. Arnon, "The therapeutic effect of TV-5010 in a murine model of inflammatory bowel disease: dextran induced colitis," International Immunopharmacology, vol. 8, no. 11, pp. 1578-1588, 2008.

[55] C. Daniel, N. A. Sartory, N. Zahn et al., "FTY720 ameliorates oxazolone colitis in mice by directly affecting T helper type 2 functions," Molecular Immunology, vol. 44, no. 13, pp. 33053316, 2007.

[56] H. Tilg and A. Kaser, "Type 1 interferons and their therapeutic role in Th2 regulated inflammatory disorders," Expert Opinion on Biological Therapy, vol. 4, no. 4, pp. 469-481, 2004.

[57] Y. Yanagihara, M. Kiniwa, K. Ikizawa et al., "Suppression of IgE production by IPD-1151T (suplatast tosilate), a new dimethylsulfonium agent: (l) regulation of murine IgE response," Japanese Journal of Pharmacology, vol. 61, no. 1, pp. 23-30, 1993.

[58] Y. Yanagihara, M. Kiniwa, K. Ikizawa, T. Shida, N. Matsuura, and A. Koda, "Suppression of IgE production by IPD-1151T (suplatast tosilate), a new dimethylsulfonium agent: (2) Regulation of human IgE response," Japanese Journal of Pharmacology, vol. 61, no. 1, pp. 31-39, 1993.
[59] M. Shichijo, Y. Shimizu, K. Hiramatsu et al., "IPD-1151T (suplatast tosilate) inhibits interleukin (IL)-13 release but not IL-4 release from basophils," Japanese Journal of Pharmacology, vol. 79, no. 4, pp. 501-504, 1999.

[60] H. Nagai, "Recent research and developmental strategy of antiasthma drugs," Pharmacology and Therapeutics, vol. 133, no. 1, pp. 70-78, 2012. 


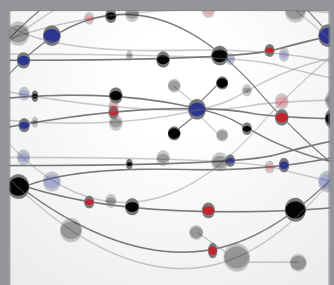

The Scientific World Journal
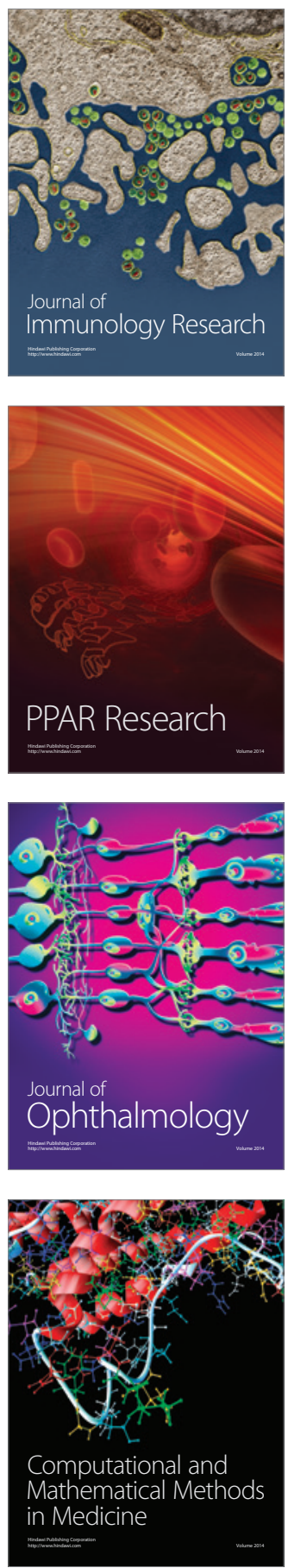

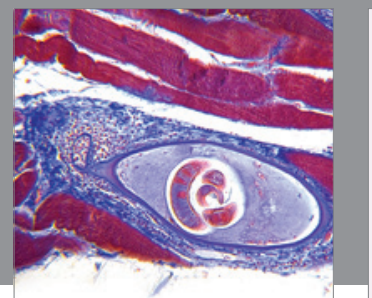

Gastroenterology

Research and Practice
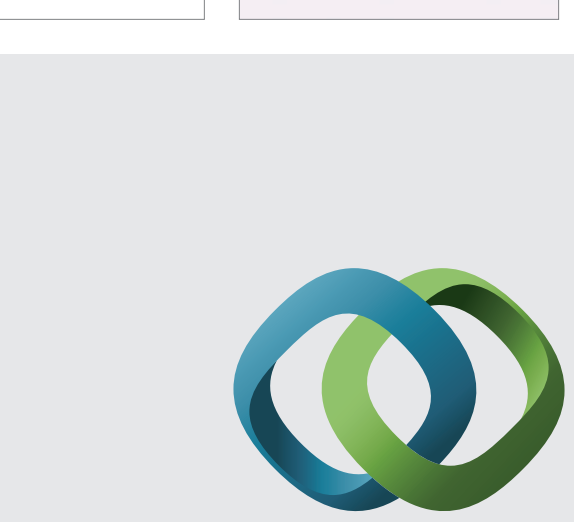

\section{Hindawi}

Submit your manuscripts at

http://www.hindawi.com
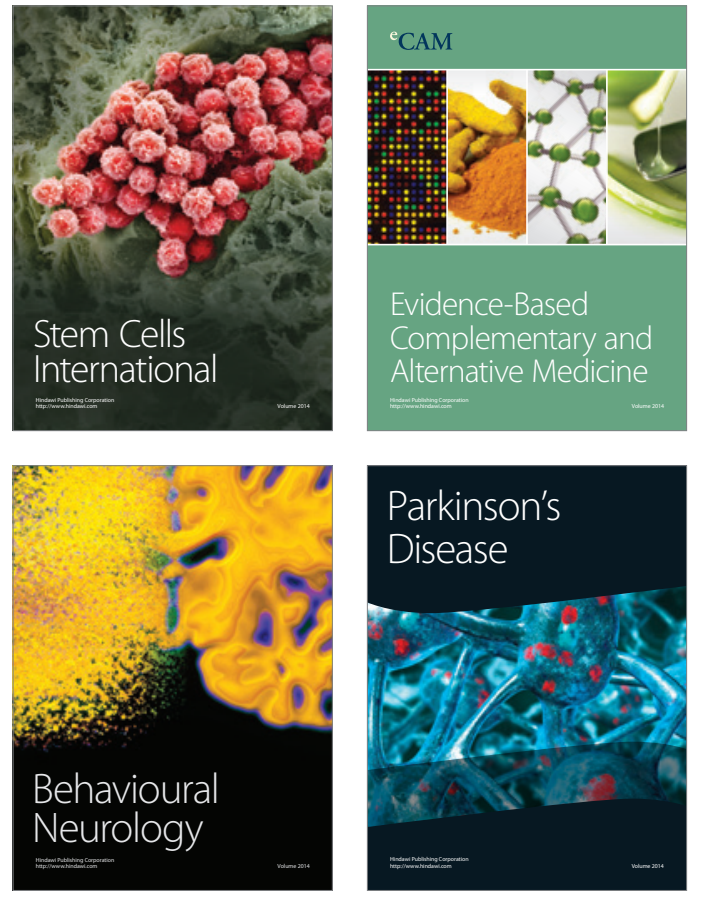
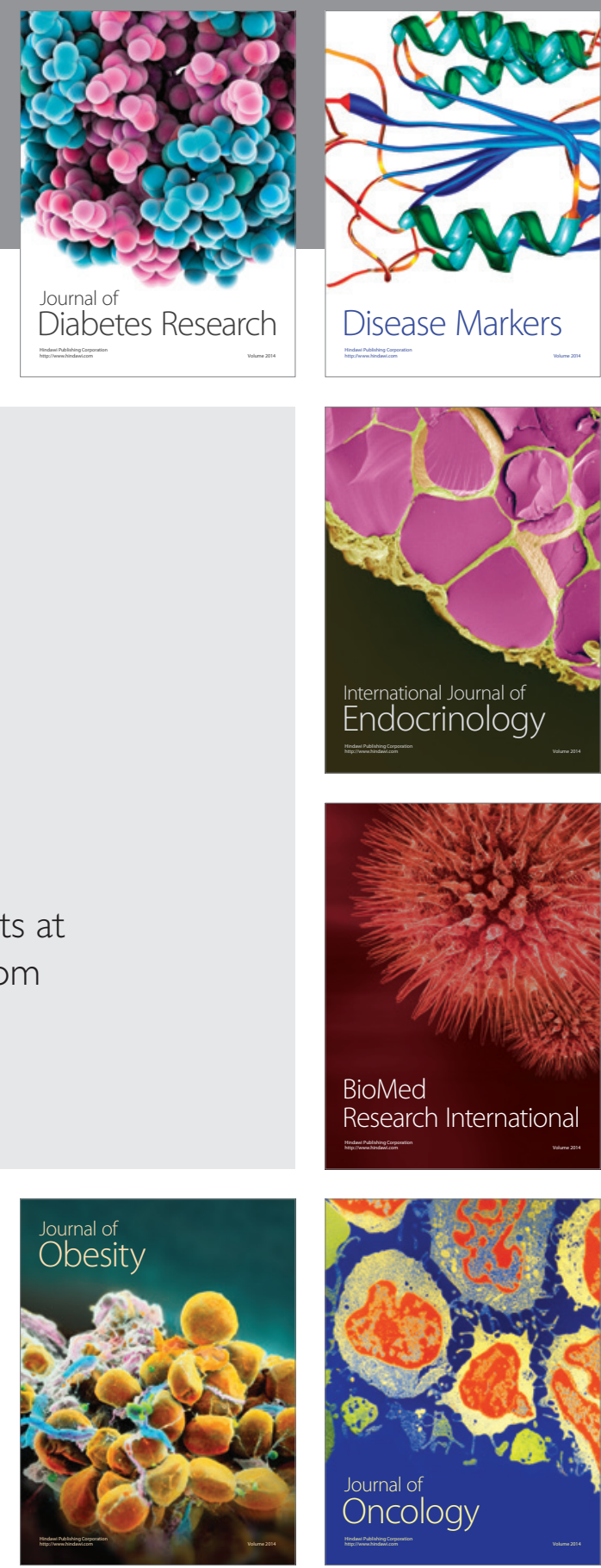

Disease Markers
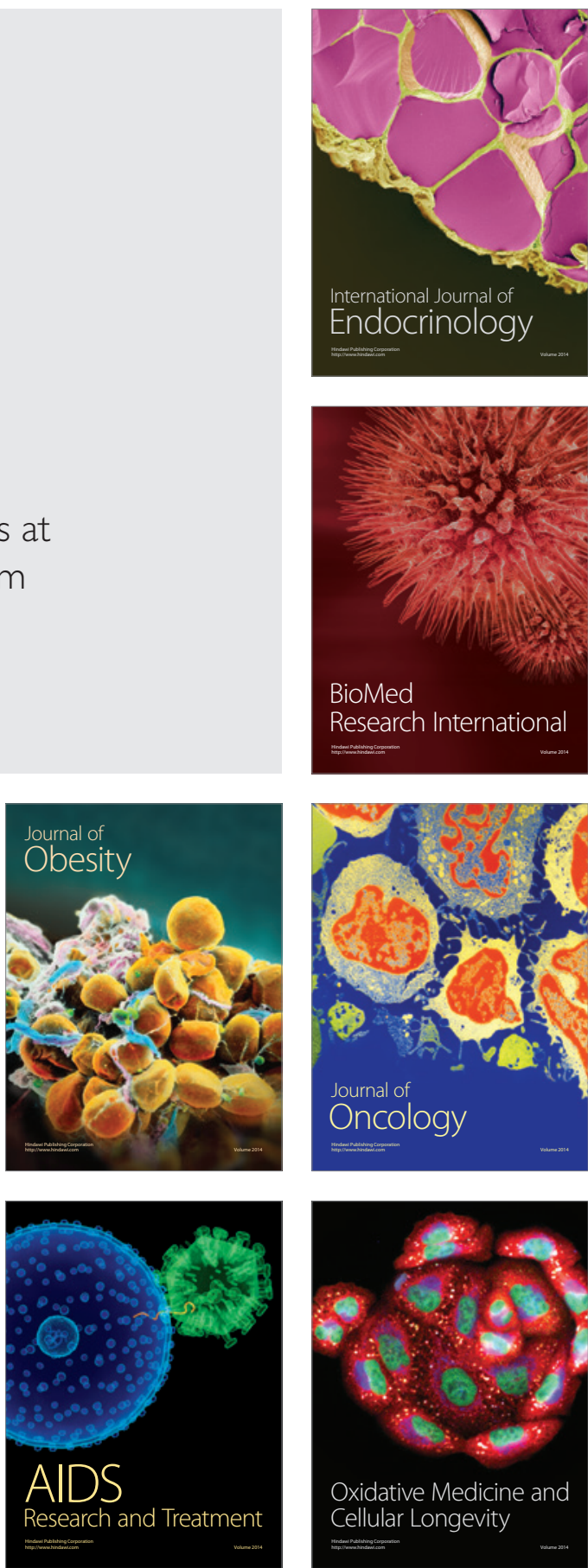